Review article

\title{
Affective touch: A meta-analysis on sex differences
}

\author{
Valentina Russo $^{\mathrm{a}, *}$, Cristina Ottaviani ${ }^{\mathrm{a}, \mathrm{b}}$, Grazia Fernanda Spitoni ${ }^{\mathrm{a}, \mathrm{b}}$ \\ a Department of Psychology, Sapienza University of Rome, Rome, Italy \\ ${ }^{\mathrm{b}}$ Santa Lucia Foundation (IRCCS Fondazione Santa Lucia), Rome, Italy
}

\section{A R T I C L E I N F O}

\section{Keywords:}

Pleasant touch

Gentle touch

C-tactile afferents

Pleasantness

\begin{abstract}
A B S T R A C T
The unmyelinated C-tactile afferents system holds a hedonic function in touch experiences, shaping social functioning in the so-called affective touch hypothesis. Despite the fact that females are recognized as more sensitive to discriminative aspects of touch and respond more positively to touch than men, sex differences in the perception of affective touch have not been extensively investigated. We aimed to fill this gap by meta-analyzing existing studies on this topic. Thirteen studies were eligible and pooled effect sizes (Hedges' g) were compared. Random effect models were used. Results, which are not influenced by publication bias, show that there is a sex asymmetry in the pleasantness perceived during an affective tactile stimulation, with females showing higher pleasantness ratings than males. The size of the association does not vary as a function of sex distribution, age and methodological quality. Hormonal as well as evolutionary differences related to the caregiving and nurturing function of females may explain sex differences in affective touch. Results are limited by the small number of studies included in the meta-analysis.
\end{abstract}

\section{Introduction}

In highly social species touch plays a central role in the formation and maintenance of relationships since it is our most social sense and the first one to develop. The hedonic properties of touch are primarily involved in improving the quality of human life (Beebe-Center, 1932): frequent affectionate touch is associated with secure attachment style (Krahé et al., 2018; Suvilehto et al., 2015), and tactile experience during childhood plays a crucial role for the development of the social brain (Cascio et al., 2019 for a recent review). For instance, lack of touch experiences in early life can produce long lasting damages like reduction of gray matter and lower quality brain activation (Nelson et al., 2014). The term social brain refers to the neuronal networks enabling our interactions with the social world: our interest in others, our sensitivity to their emotions and thoughts, and our ability to interact with them (Brauer et al., 2016). The somatosensory system includes an affective dimension that overcomes the functional and anatomical role of discriminative somatosensory networks, and the core of such dimension seems to be related to unmyelinated C-tactile afferents, present in hairy but not in the glabrous skin (Liu et al., 2007; Olausson et al., 2010), which respond strongly to innocuous skin deformation (Vallbo et al., 1999). The most accredited hypothesis regarding the functional role of the C-tactile system is known as the Affective Touch hypothesis, according to which the C-tactile afferents system boost the emotional effects of physical closeness to a friendly person, supporting feelings of pleasure, protection and security (Vallbo et al., 2016). Ctactile afferents hold a hedonic function in tactile experiences, showing a preferential response rate when the stimulation occurs at skin-like temperatures $\left(32^{\circ} \mathrm{C}\right.$ ) (Ackerley et al., 2014a) delivered at caress-like velocities (3 or $5 \mathrm{~cm} / \mathrm{s}$ ) (Essick et al., 1999; Löken et al., 2009), which are typical characteristics of human caress. C-tactile afferents' input is rewarding since there is a high correlation between subjective pleasantness perceived during a slow stimulation and their impulse rate (Löken et al., 2009; Wessberg et al., 2003). Social touch behaviors in mammals is modulated by several hormones, such as opioids like the $\mu \mu$-opioid receptor (MOR) and the neuropeptide oxytocin, which in turn reduces cortisol release (e.g., Colonnello et al., 2017; Ellingsen et al., 2016 for narrative reviews; Walker and McGlone, 2013; Walker et al., 2017). For instance, opioid blockade modulates the perception of pleasantness of slow CT-optimal touch (Case et al., 2016), and intranasal oxytocin administration regulates social evaluations of others after being touched (Ellingsen et al., 2013).

Importantly, the preference for a C-tactile optimal stimulation has been seen both in adults and children (5-8 years old), showing that affective touch is perceived as more pleasant already at a young age (Croy et al., 2019; Sehlstedt et al., 2016). On the other hand, the presence of a sex asymmetry during tactile experiences has emerged: in general, women tend to respond more positively to touch than men

\footnotetext{
* Corresponding author at: Department of Psychology, Sapienza University of Rome, Via dei Marsi, 78, 00182 Rome, Italy.

E-mail address: russo.1742773@studenti.uniroma1.it (V. Russo).
} 
(Stier and Hall, 1984) and they seem to experience more positive touch through their life than men (Takeuchi et al., 2010; Webb and Peck, 2015). Overall, women seem to be more prone to reactive behaviors, such as allowing oneself to be touched, while men seem to be more familiar with proactive behaviors, such as initiating touch (Major, 1981). Comparing same-sex and cross-sex touching behaviors, men are more likely to initiate touch when the one being touched is a woman (Henley, 1973). When they touch, women are rated as more affectionate, trusting, happy, and composed than men (Lee and Guerrero, 2001).

A sex asymmetry also emerges in the perceived valence of a touch; for example, women are more likely to appreciate a stranger toucher, provided that the touch is nonsexual, compared to men (Hall et al., 2005; Hertenstein et al., 2006). Furthermore, when two individuals have an equal professional status, there seems to be a sex asymmetry in touch with males being touchers more often than females (Hall, 1996). These findings suggest that men and women interpret touch differently: men may tend to interpret touch initiated by an equal status stranger as dominance input, while women may interpret it as a warm and friendly gesture (Major, 1981). The view that touching behavior is an expression of dominance is also supported by studies showing a sex by with cultural differences interaction in determining touching behavior (e.g., Dibiase and Gunnoe, 2004). It has to be noted, however, that similarities of emotional bonding via social touch between different cultures (i.e., East Asian and Western) have been reported (Suvilehto et al., 2019). Despite such cultural similarities, the effect of context should always be taken into account when examining interpersonal affective touch. On the basis of situational variables (e.g., inferences about the identity or intentions of the toucher), certain tactile interactions can also be perceived as appropriate or inappropriate. Studies showed, for example, how touch pleasantness can be modulated by the presence of smiling faces or pleasant odors (Ellingsen et al., 2013; Croy et al., 2014). Similarly, heterosexual men rate touch as more pleasant when it is delivered by a woman compared to a man (Gazzola et al., 2012; Scheele et al., 2014).

Data also support the presence of sex differences in the accuracy of communicating emotions via touch: in particular, sex-related differences have been observed for emotions like happiness, sympathy and anger. It seems that women can successfully communicate sympathy and happiness briefly touching the arm of a stranger, while the same is true for men regarding anger communication (Hertenstein and Keltner, 2011).

Females also show different affective responses compared to males for tactile stimulations delivered with various texture materials to different body sites. In general, males and females rated texture materials that were smooth or soft (e.g. cupro and cotton interlock) with similar pleasantness ratings, especially if the stimulation occurred on the hand, forearm or thigh. However, sex differences were found for textured materials that were rough or coarse (e.g. terry toweling and denim): males found denim and terry toweling less pleasant on the forehead, while females found them most unpleasant on the thigh and hand (Essick et al., 2010).

Regarding affective touch there is less clear evidence about sex asymmetries. Most of the studies do not find significant effects of participants sex on their pleasantness ratings, with CT optimized touch usually perceived as significantly more pleasant than non-optimized tactile stimulations (e.g., Croy et al., 2014; Jönsson et al., 2015; Sehlstedt et al., 2016; Triscoli et al., 2013). However, recent studies have shown that females are more sensitive to affective touch, as well as to discriminative aspects of touch. In fact, females rated affective touch and non-affective touch stimuli as more pleasant and had higher tactile acuity than males. This difference was not correlated to hair follicle density, which is higher in women than men (Jönsson et al., 2017).

Lastly, women seem to differ from men even regarding pain perception, being more sensitive to small temperature changes, to heat pain and cold pain (Meh and Denišlič, 1994); in general, they show a greater sensitivity to pain, being better able to discriminate the intensity of noxious heat stimuli (Feine et al., 1991). On this account, some studies have highlighted the existence of a relationship between affective touch and pain. In fact, CT-targeted touch reduces heat pain, suggesting that pain perception can be modulated by the activity of the affective touch system. Moreover, it seems that the role of C-tactile afferents may be disrupted while an injury or an inflammation of the skin are going on, inducing a reversion of their activity into a signal of negative affective sensations in the so called "hedonic flip" (Liljencrantz and Olausson, 2014).

To date, despite the fact that reported evidences highlight the presence of a sex asymmetry in the perception of affective touch, there are conflicting results as well, with some studies reporting no differences at all. Furthermore, it appears that sex differences in perception of affective touch have not been quantified likely due to the small number of studies on this topic.

In order to fill this gap, a meta-analysis was performed with the aim of quantifying sex differences in the perception of pleasantness during affective touch stimulation. Given the evidences reported so far, the present study hypothesized that females are more sensitive to affective touch than males and thus that their subjective pleasantness ratings associated with affective touch stimulation are higher than those of males.

\section{Methods}

\subsection{Literature search and study selection}

Two search strategies were used to systematically collect empirical studies on affective touch. First, pubMED (https://www.ncbi.nlm.nih. gov/pmc/) and psycINFO (http://www.apa.org) database were searched for English-language publications through June 21 2017. One single search was conducted for the following key words: affective touch OR pleasant touch OR gentle touch.

The search was limited to English-language publications and human samples. Inclusion criteria for our analysis were as follows: (a) measures of pleasantness perceived during affective touch stimulation, (b) sample composed of both males and females, and (c) defined stimulation speed ( 3 or $5 \mathrm{~cm} / \mathrm{s})$.

Reasons for exclusion were: (a) review articles, (b) case reports, (c) studies conducted only on clinical populations, (d) grey literature and (e) studies conducted on children. Each study was included just once in the meta-analysis.

A total of 270 articles were found. After applying inclusion and exclusion criteria, 67 articles results were retrieved. Comparison of the retrieved titles, identified 24 studies that were duplicates, thus leaving 43 abstracts for further evaluation (see Fig. 1). In order to perform the meta-analysis, separate pleasantness ratings, divided by sex, were needed; since none of the 43 studies provided such information, we contacted the corresponding authors for additional data. Among the 43 studies, the requested data was received for 12 studies and one more study was added following the suggestion of one author (Ackerley et al., 2014b), totaling 13 studies. Thus, the current meta-analysis is based on data provided by the authors of the 13 studies that met the inclusion criteria, for the main analysis, and data directly extracted from the aforementioned studies, for moderation analysis (see Table 1).

\subsection{Coding and moderator analysis}

The quality of evidence was assessed with a modified version of the Newcastle-Ottawa Scale (NOS; Wells et al., 2011). In our modified NOS scale, the maximum score that could be achieved by a study was 7 stars (see Appendix).

We examined how size of the association varied as a function of sex distribution (\% of women), mean age (years), number of trials (number of stimulations; i.e., number of total affective touch stimulations given 


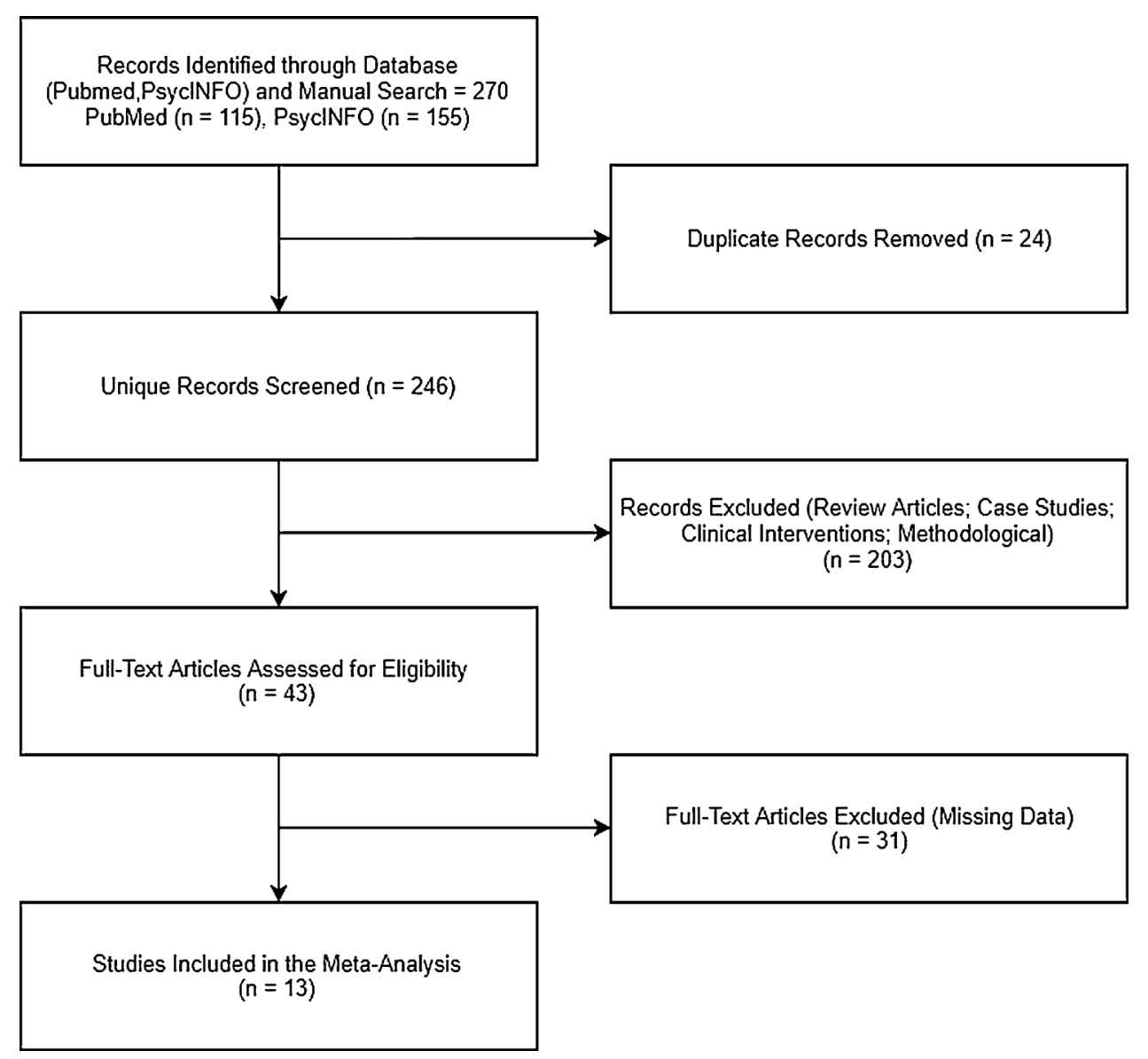

Fig. 1. Flow chart showing study selection for the meta-analysis.

in the whole experimental paradigm), methodological quality (0-7), stimulation speed $(\mathrm{cm} / \mathrm{s})$, and stimulation type (hand or robot). A minimum of four studies for each subgroup was required for the moderation analysis.

Continuous moderators (i.e. sex distribution and age) were evaluated using metaregression, while categorical moderators (stimulation type, methodological quality and number of stimulations) were entered as grouping variables in the effect size calculations.

\subsection{Data analysis}

For each study (or subsample of a study), we calculated a Hedges' $\mathrm{g}$ effect size. Based on conventional standards, effect sizes of $g$ equal to $.20, .50$, and .80 were considered small, medium, and large, respectively (Cohen, 1988). Calculation of effect sizes was based on means and standard deviations.

The effect sizes were computed in ProMeta Version 3.0 (Internovi). Random-effects models were used in all the analyses as they account for the amount of variance caused by differences between associations as well as differences among participants within associations. ProMeta also computed $95 \%$ confidence intervals $(C I)$ around the point estimate of an effect size. The $Q$ and $I^{2}$ statistics were used to assess heterogeneity among studies. A significant $Q$ value indicates a lack of homogeneity of findings among studies. $I^{2}$ values of .25 , .50, and .75 correspond to low, moderate, and high between-trial heterogeneity, respectively.

Publication bias occurs when the decision to publish an experiment or research study is influenced by its outcome; in particular, professional journals tend to publish papers with statistically significant results rather than studies with null or inconclusive results (Song et al., 2013). The problem of publication bias was estimated first informally, by using a funnel plot of effect size against standard error for asymmetry, and subsequently formally by using Begg and Mazumdar's rank correlations, and Egger's regression intercept test. Finally, we decided not to rely on fail-safe number $(\mathrm{N})$, or file-drawer number, even though it is the second most used method to assess publication bias. This choice was made because, for this purpose, it has been considered inadequate and problematic (e.g., Becker, 2005). In fact, as reported by Higgins and Green (2011), the estimate of fail-safe N is highly dependent on the assumed mean effect for the unpublished studies and runs against the principle to concentrate on the size of the estimated effect and the associated confidence intervals, rather than on whether the $p$ value reaches a particular, arbitrary threshold.

Since the main aim of a meta-analysis is to aggregate over all data, analyses including the entire set of studies were run. Statistics reported in this meta-analysis conformed to the Preferred Reporting Items for Systematic Reviews and Meta-Analyses (PRISMA; Moher et al., 2010) statement (PRISMA checklist available from the first author upon request).

\section{Results}

Table 1 shows all studies included in the current meta-analysis, moderators and conditions or comparisons used to derive effect sizes.

As shown in Fig. 2, the meta-analysis showed a significant difference between males and females with women rating affective touch as more pleasant than men (13 studies; 362 subjects; $g=.25$, 95\% CI [.04, .46], $\mathrm{p}=.022$ ).

Heterogeneity was not significant, as shown by the $Q$ and $I^{2}$ statistics, $Q(12)=10.56, p=.567 ; I^{2}=.00$. We did not find evidence of asymmetry using a classic funnel plot (see Fig. 3). Kendall's tau did not detect the presence of a publication bias $(Z=.61 ; p=.542)$ and this 
was further confirmed by Egger's regression test (Intercept $=.19$, $t=.16, p=.876)$. No potential outliers emerged in this meta-analysis.

\subsection{Moderation analysis}

Unfortunately, almost all studies had a stimulation speed of $3 \mathrm{~cm} / \mathrm{s}$, thus not allowing for moderation analysis. Results of the present metaanalysis did not differ based on sex distribution $(p=.697)$, mean age $(p=.863)$, number of trials $(p=.578)$, methodological quality $(p=.807)$, or stimulation type $(p=.748)$.

The study by Triscoli et al. (2013) was excluded from the moderation analysis on stimulation type because results were based on both robot and hand stimulations. The studies by Etzi et al. (2014), Etzi and Gallace (2016) were excluded from this analysis as well, because different kinds of textures, which are not compatible with the soft brushes used in other studies, were used. The study of Sailer et al. (2016) was excluded from the moderation analysis on number of trials because they did not use a defined number of stimulations, but they performed stroking on each subject for $40 \mathrm{~min}$.

Sex distribution was not a significant moderator, even though 5 out of 13 studies used samples composed mostly of females; this means that results are not influenced by the percentage of females or males.

Mean age did not play a significant role as a moderator because most of the studies included participants in their $20 \mathrm{~s}$. Moreover, it has been previously suggested that the affective processing of pleasant touch is a stable disposition (Sehlstedt et al., 2016).

The number of stimulations was not a significant moderator of sex differences in affective touch; however, 4 studies applied just 3 affective touch stimulations while 8 studies used more than 3 affective touch stimulations. Nevertheless, it must be noted that continuous stimulations seem to be unsuited to study affective touch. In fact, C-tactile afferents may need time between stimulations to not be fatigued and it seems that following a series of 2 or 3 successive stimulations (as happens in the majority of the analyzed studies) the response settles to a submaximal level which can last even for a long time (Iggo, 1960). However, further evidences have proved that touch satiety occurring after a $\mathrm{C}$ tactile-optimal stroking $(3 \mathrm{~cm} / \mathrm{s})$ requires some time and it does not produce unpleasant feelings, meaning that pleasant touch is robust against sensory satiety (Triscoli et al., 2014). This evidence was even further supported by results of a recent study, included in our meta-analysis, showing that even after $40 \mathrm{~min}$ of continuous affective touch, participants did not perceive the stroking as unpleasant (Sailer et al., 2016).

As to type of stimulation, previous studies also suggest that human and robotic tactile stimulations lead to similar pleasantness ratings for C-tactile optimized skin stroking, even though people are aware of the stimulation's source (Triscoli et al., 2013).

Lastly, methodological quality, measured by NOS scale, was not a significant moderator. The reason why none of the studies received the maximum number of stars was mostly due to the small sample sizes used.

\section{Discussion}

In recent years, affective touch and its neurophysiological correlates have received great attention. C-tactile fibers allow the perception and the conduction of affective interpersonal touch and it seems that people tend to spontaneously caress the skin of their partner or children at a velocity that falls within the optimal range for the activation of C-tactile afferents (Croy et al., 2016). Although, to date, sex asymmetry in touch perception has not received solid validations, the present meta-analytic results show that affective touch is experienced differently in males and females. Hence, our hypothesis that females rate affective touch as more pleasant than males was supported by the data. Unfortunately, the number of studies that could have been potentially included in the analysis was limited due to the fact that sex differences are not usually 


$\begin{array}{rr} & 95 \% \text { Cl } \\ \text { Ackerley et al. 2014a } & -0.56 / 0.75 \\ \text { Ackerley et al. 2014b } & -0.17 / 1.25 \\ \text { Case et al. 2016 } & -1.09 / 1.24 \\ \text { Croy et al. 2014 } & 0.16 / 1.36 \\ \text { Ellingsen et al. 2013 } & -0.34 / 0.88 \\ \text { Etzi et al. 2014 } & -1.48 / 1.32 \\ \text { Etzi et al. 2016 } & -0.79 / 0.89 \\ \text { Hielscher et al. 2016 } & -0.53 / 0.91 \\ \text { Kass-lliyya et al. 2016 } & -0.40 / 1.10 \\ \text { Loken et al. 2011 } & -0.91 / 0.77 \\ \text { Iwlacefield et al. 2014 } & 0.11 / 2.45 \\ \text { Sailer et al. 2016 } & -0.72 / 0.82 \\ \text { Triscoli et al. 2013 } & -0.99 / 0.39 \\ \text { Overall (random-effects model) } & 0.04 / 0.46\end{array}$

$95 \% \mathrm{Cl}$

$-0.56 / 0.75$

$-0.17 / 1.25$

$-1.09 / 1.24$

$0.16 / 1.36$

$-0.34 / 0.88$

$-1.48 / 1.32$

$-0.79 / 0.89$

$-0.53 / 0.91$

$-0.40 / 1.10$

$-0.91 / 0.77$

$0.11 / 2.45$

$-0.72 / 0.82$

$0.04 / 0.46$

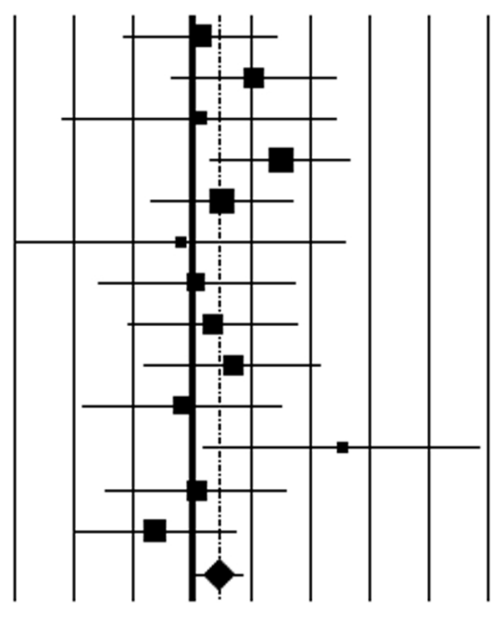

$\begin{array}{lllllllll}-1.5 & -1 & -0.5 & 0 & 0.5 & 1 & 1.5 & 2 & 2.5\end{array}$
Fig. 2. Forest Plot. For each study included in the meta-analysis, boxes represent the size of the study (studies with larger samples are depicted with bigger boxes), whereas horizontal lines represent the $95 \%$ confidence interval (CI) of each study result. The vertical line (y-axis), known as the "line of null effect", indicates the absence of difference between the two examined groups (males and females) in affective touch. The diamond at the bottom of the forest plot represents the point estimate and confidence interval (its width) resulting from the combination of all individual studies. analyzed and/or reported in these studies.

This finding is in line with previous studies not included in the present meta-analysis showing that women respond more positively to touch than men (Stier and Hall, 1984) and perceive affective touch as more pleasant than men (Jönsson et al., 2017).

Several factors may contribute to these differences, including hormones, genetics and psychological factors, and it seems plausible that these differences are not entirely explained by social and cultural costumes. In fact, it has been shown that young girls perceive touch to be more pleasant than boys (Croy et al., 2019) and it is unlikely that social or cultural factors have already and entirely biased their behavior.

It seems that C-tactile afferents are involved in the conduction of erotic touch as well (Kandel et al., 2013). Even though the presence of C-tactile afferents in the genital area has not been confirmed yet, erotic genital touch activates the same area in posterior insula activated by Ctactile afferents sensations (Georgiadis and Holstege, 2005; Georgiadis et al., 2010). In fact, the highest eroticism ratings are maximally associated with CT-optimal touch, which mediates sexual desire and performance in a sex specific-way. Apparently, women tend to interpret slow touch as a sexual cue while men tend to interpret it as a sexual reward (Bendas et al., 2017). Moreover, it seems that women rate touch as more erotic compared to men (Jönsson et al., 2015). The finding that erotic touch perception relates to sexual desire and sexual performance in a sex-specific way may support the hypothesis that sex asymmetry in the perception of affective touch is in part independent from cultural or social bias.

A possible interpretation of sex differences in the evaluation of affective touch may be related to sex hormones and more specifically to the higher presence of testosterone in men. In fact, testosterone has always been associated with hunting (Worthman and Konner, 1987; Trumble et al., 2014) and dominance behavior (Mazur and Booth, 1998). It has been proven that men with lower levels of testosterone are more sensitive to touch, while higher levels of this hormone are associated with reduced tactile sensitivity (Burris et al., 1991). As the authors suggest, the chronic exposure to testosterone to which men undergo, for example during puberty, may produce the aforementioned reduction in tactile sensitivity (Burris et al., 1991). It has been shown that testosterone levels are inversely correlated with paternal affectionate touch since it appears that fathers with high levels of testosterone are less likely to touch their infants (Weisman et al., 2014). On this account, fatherhood seems to be negatively related to testosterone levels; in fact, fathers have lower levels of testosterone compared to

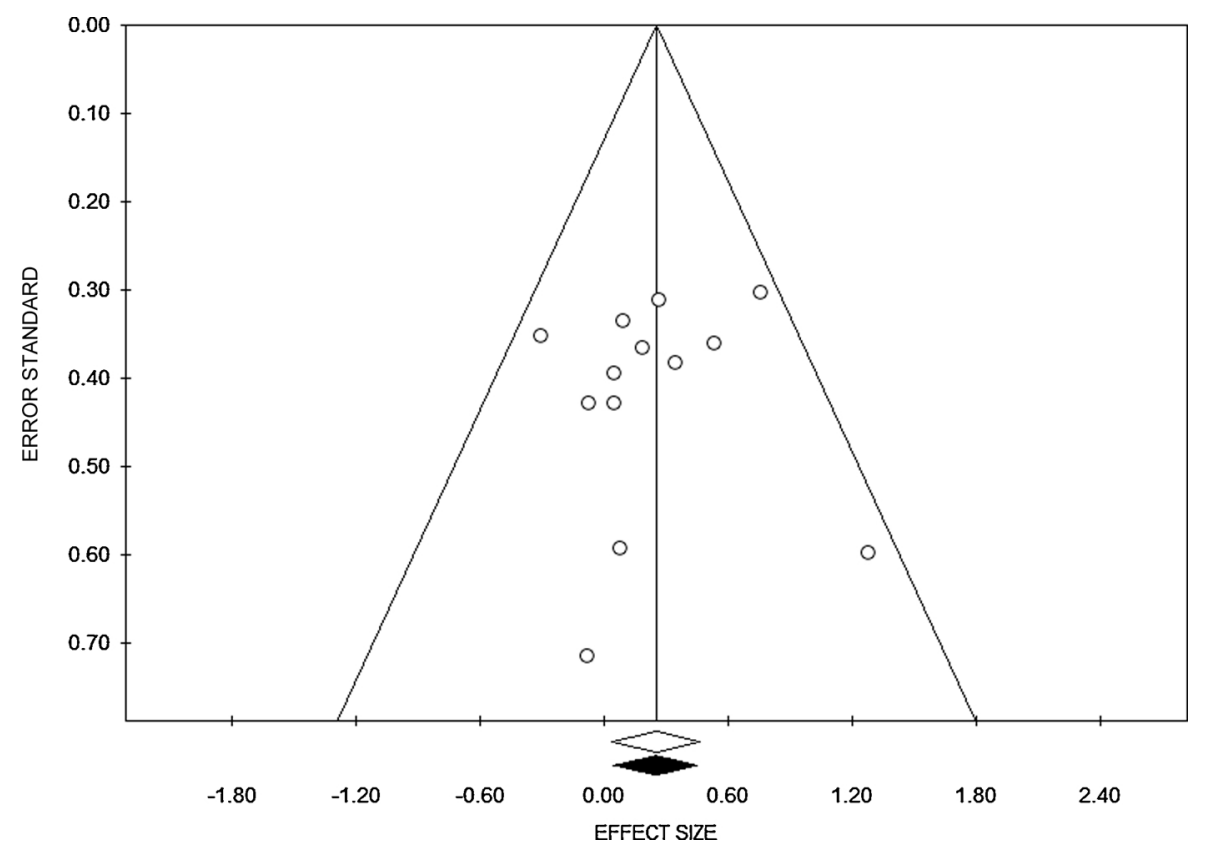

Fig. 3. Funnel Plot. Each dot represents a single study; the y-axis represents the standard error of effect estimate with larger studies placed towards the top. The $\mathrm{x}$ axis shows the result for each study. In the absence of bias and between study heterogeneity, the scatter is due to sampling variation alone and the plot resembles a symmetrical inverted funnel. The open and filled diamonds overlap meaning that the estimated number of missing studies is negligible. 
men without children (Grebe et al., 2019). This decrease is thought to promote parenting behaviors (Edelstein et al., 2015; Fleming et al., 2002; Gray et al., 2002; Perini et al., 2012). Thus, increased testosterone may be functional for indirect forms of paternal care since it facilitates aggressive defense of infants when there is a treat, while on the other hand it may interfere with more direct forms of caregiving such as holding and cuddling (van Anders et al., 2012).

Another possible interpretation of our results may be related to the fact that females have evolved as caregivers and nurtures, since they are typically involved in the creation of the maternal bonding with offspring and to the so called maternal sensitivity, that is mother's ability to perceive and accurately interpret her infant's signals and respond appropriately and promptly (Ainsworth et al., 1978). In fact, compared to males, women share a peculiar tactile relationship with their children, which starts already within the womb (Field, 2010 for a review). It has been proposed that $\mathrm{CT}$ afferents are prematurely stimulated by the movements of fetal lanugo hairs induced by the amniotic fluid (Bystrova, 2009); moreover, mothers automatically touch their abdomen in order to calm, stimulate and interact with the fetus, which in turn tend to move towards the touched area (Marx and Nagy, 2017). Maternal stroking has been implicated in the development of the social brain and thus it has a great influence on social behavior development (Jean et al., 2009). In particular, affective touch is considered to be the scaffolding through which the social brain is shaped (Crucianelli and Filippetti, 2018) and it has been proved that parents tend to spontaneously activate the affective touch system during tactile interaction with their own child (Croy et al., 2016). In general, all existing studies point to the notion that maternal tactile interactions play a crucial role for infants' mental and physical health (e.g. Sharp et al., 2012; Maitre et al., 2017).

Mothers adapt their tactile behaviour to the age of their infants (Jean et al., 2009) and use different types of touch (Ferber et al., 2008; Stack and Muir, 1992; Stack et al., 1996), eliciting specific responses in their infants, and in turn infants become sensitive to their mother's touch (Stack and Muir, 1992). The frequency of touch during playing sessions between mothers and their five-year-old children appears to be associated with the strength of connectivity of the posterior superior temporal sulcus and other nodes in the social brain (Brauer et al., 2016). However, frequency of tactile interactions itself does not influence attachment between mother and infants, whereas what is important is the kind of touch which is mostly used: in fact, nurturing and affectionate touch is associated with secure attached infants (Weiss et al., 2000).

Furthermore, it appears that mothers might be able to regulate their infants' emotions using touch (Hertenstein and Campos, 2001); indeed, mothers who are unable to understand and interpret their infants' needs show non-attuned tactile interactions with them (Crucianelli and Filippetti, 2018). These results highlight the importance of an optimal tactile relationship, which is supported by maternal tactile sensitivity, for offspring well-being.

To sum up, maternal cuddling and caressing strengthen the relationship between mother and child, and maternal touch is critical for offspring development; thus, it is plausible that females have a greater sensitivity to affective touch - which is already functional early in life in order to create optimally adaptive tactile relationships.

\subsection{Limitations and conclusions}

One of the most important limitations of the present study is the small number of available studies; likely due to the fact that studies on affective touch are only relatively recently increasing in number. Moreover, in order to perform the analysis, we needed subjective pleasantness measures provided by healthy subjects - both males and females - during a CT-optimal stimulation delivered in a neutral condition; these criteria reduced consistently the number of available studies. A further limitation of our study was that we did not include studies published in languages other than English. Also, we did not include gray literature like working papers, white papers or reports. Fortunately, our analyses suggest that publication bias is unlikely to have influenced our results.

To conclude, the present meta-analysis supports that women rate affective touch as more pleasant than men. The small size of the effect points to the need for more studies on this topic. In particular, such studies should include both males and females in their sample and have larger samples. Moreover, future studies should include objective measures, such as neuronal firing or brain activation, in order to explore the origin of the sex differences found in the present meta-analysis. Furthermore, it could be of interest the exploration of the effect of the stimulus materials (i.e. classic brush, cotton, silk) in the evaluation of tactile pleasantness among women and men.

Lastly, despite the absence of publication bias, it should be noted that results reported in our study may be potentially influenced by a selection bias. In fact, it is possible that the examined studies do not report analysis on sex differences because these are statistically nonsignificant. This consideration should sensitize authors to report, whenever possible, information regarding sex differences in the perception of affective touch.

\section{Declaration of Competing Interest}

None.

Appendix A. Adapted version of the Newcastle-Ottawa scale used in the present study for quality assessment (maximum 7 stars)

\section{Selection: (Maximum 2 stars)}

\section{1) Representativeness of the general population sample:}

2) Truly representative of the average in the target population. * (all subjects or random sampling)

3) Somewhat representative of the average in the target population. * (non-random sampling)

4) Selected group of users.

5) No description of the sampling strategy.

6) Sample size:

7) Satisfactory. * (MIN 30)

8) Not satisfactory.

\section{Measurement of the predictor (s) (Maximum 2 stars)}

a) The tool is available or described.**

b) No description of the measurement tool.

Outcome: (Maximum 3 stars) VAS

\section{1) Assessment of the outcome:}

2) Detailed description. **

3) No description.

4) Statistical test:

5) The statistical test used to analyze the data is clearly described and appropriate, and the measurement of the association is presented, including confidence intervals and the probability level ( $\mathrm{p}$ value). *

6) The statistical test is not appropriate, not described or incomplete.

\section{Appendix B. Supplementary data}

Supplementary material related to this article can be found, in the online version, at doi:https://doi.org/10.1016/j.neubiorev.2019.09. 037. 


\section{References}

*Ackerley, R., Carlsson, I., Wester, H., Olausson, H., Backlund Wasling, H., 2014a. Touch perceptions across skin sites: differences between sensitivity, direction discrimination and pleasantness. Front. Behav. Neurosci. 8 (54). https://doi.org/10.3389/fnbeh. 2014.00054.

*Ackerley, R., Backlund Wasling, H., Liljencrantz, J., Olausson, H., Johnson, R.D., Wessberg, J., 2014b. Human C-Tactile afferents are tuned to the temperature of a skin-stroking caress. J. Neurosci. 34 (8), 2879-2883. https://doi.org/10.1523/ JNEUROSCI.2847-13.2014.

Ainsworth, M.S., Blehar, M., Waters, E., Wall, S., 1978. Patterns of Attachment: A Psychological Study of the Strange Situation. Erlbaum, Hillsdale, NJ.

Becker, B.J., 2005. Failsafe N or file-drawer number. In: Rothstein, H.R., Sutton, A.J., Borenstein, M. (Eds.), Publication Bias in Meta-Analysis: Prevention, Assessment and Adjustments. Wiley, Hoboken, pp. 111-125.

Beebe-Center, J.G., 1932. The Psychology of Pleasantness and Unpleasantness. D. Van Nostrand, New York. https://doi.org/10.1037/13344-000.

Bendas, J., Georgiadis, J.R., Ritschel, G., Olausson, H., Weidner, K., Croy, I., 2017. Ctactile mediated erotic touch perception relates to sexual desire and performance in a gender- specific way. J. Sex. Med. 14 (5), 645-653. https://doi.org/10.1016/j.jsxm. 2017.02.016.

Bystrova, K., 2009. Novel mechanism of human fetal growth regulation: a potential role of lanugo, vernix caseosa and a second tactile system of unmyelinated low-threshold C-afferents. Med. Hypotheses 72 (2), 143-146.

Brauer, J., Xiao, Y., Poulain, T., Friederici, A.D., Schirmer, A., 2016. Frequency of maternal touch predicts resting activity and connectivity of the developing social brain. Cereb. Cortex 26 (8), 3544-3552. https://doi.org/10.1093/cercor/bhw137.

Burris, A.S., Gracely, R.H., Carter, C.S., Sherins, R.J., Davidson, J.M., 1991. Testosterone therapy is associated with reduced tactile sensitivity in human males. Horm. Behav. 25, 195-205.

Cascio, C.J., Moore, D., McGlone, F., 2019. Social touch and human development. Dev. Cogn. Neurosci. 35, 5-11. https://doi.org/10.1016/j.dcn.2018.04.009.

*Case, L.K., Čeko, M., Gracely, J.L., Richards, E.A., Olausson, H., Bushnell, M.C., 2016 Touch perception altered by chronic pain and by opioid blockade. eNeuro 3 (1). https://doi.org/10.1523/ENEURO.0138-15.2016. ENEURO.0138-15.2016.

Cohen, J., 1988. Statistical Power Analysis for the Behavioral Sciences, second ed. Routledge, New York.

Colonnello, V., Petrocchi, N., Farinelli, M., Ottaviani, C., 2017. Positive social interactions in a lifespan perspective with a focus on opioidergic and oxytocinergic systems: implications for neuroprotection. Curr. Neuropharmacol. 15 (4), 543-561.

*Croy, I., D'Angelo, S., Olausson, H., 2014. Reduced pleasant touch appraisal in the presence of a disgusting odor. PLoS One 9 (3), e92975. https://doi.org/10.1371/ journal.pone.0092975.

Croy, I., Luong, A., Triscoli, C., Hofmann, E., Olausson, H., Sailer, U., 2016. Interpersonal stroking touch is targeted to C tactile afferent activation. Behav. Brain Res. 297 37-40. https://doi.org/10.1016/j.bbr.2015.09.038.

Croy, I., Sehlstedt, I., Wasling, H.B., Ackerley, R., Olausson, H., 2019. Gentle touch perception: from early childhood to adolescence. Dev. Cogn. Neurosci. 35, 81-86. https://doi.org/10.1016/j.dcn.2017.07.009.

Crucianelli, L., Filippetti, M.L., 2018. Developmental perspectives on interpersonal affective touch. Topoi 1-12. https://doi.org/10.1007/s11245-018-9565-1.

Dibiase, R., Gunnoe, J., 2004. Gender and culture differences in touching behavior. J. Soc. Psychol. 144, 49-62.

Edelstein, R.S., Wardecker, B.M., Chopik, W.J., Moors, A.C., Shipman, E.L., Lin, N.J., 2015. Prenatal hormones in first-time expectant parents: longitudinal changes and within-couple correlations. Am. J. Hum. Biol. 27 (3), 317-325.

Ellingsen, D.M., Leknes, S., Løseth, G., Wessberg, J., Olausson, H., 2016. The neurobiology shaping affective touch: expectation, motivation, and meaning in the multisensory context. Front. Psychol. 6, 1986. https://doi.org/10.3389/fpsyg.2015. 01986.

*Ellingsen, D.M., Wessberg, J., Chelnokova, O., Olausson, H., Laeng, B., Leknes, S., 2013. In touch with your emotions: oxytocin and touch change social impressions while others' facial expressions can alter touch. Psychoneuroendocrinology 39 (1), 11-20. https://doi.org/10.1016/j.psyneuen.2013.09.017.

Essick, G.K., James, A., McGlone, F.P., 1999. Psychophysical assessment of the affective components of non-painful touch. Neuroreport 10 (10), 2083-2087.

Essick, G.K., McGlone, F., Dancer, C., Fabricant, D., Ragin, Y., Phillips, N., Jones, T., Guest, S., 2010. Quantitative assessment of pleasant touch. Neurosci. Biobehav. Rev. 34, 192-203. https://doi.org/10.1016/j.neubiorev.2009.02.003.

*Etzi, R., Gallace, A., 2016. The arousing power of everyday materials: an analysis of the physiological and behavioral responses to visually and tactually presented textures. Exp. Brain Res. 234 (6), 1659-1666. https://doi.org/10.1007/s00221-016-4574-z.

*Etzi, R., Spence, C., Gallace, A., 2014. Textures that we like to touch: an experimental study of aesthetic preferences for tactile stimuli. Conscious. Cogn. 29, 178-188. https://doi.org/10.1016/j.concog.2014.08.011.

Feine, J.S., Bushnell, M.C., Miron, D., Duncan, G.H., 1991. Sex differences in the perception of noxious heat stimuli. Pain 44 (3), 255-262.

Ferber, S.G., Feldman, R., Makhoul, I.R., 2008. The development of maternal touch across the first year of life. Early Hum. Dev. 84 (6), 363-370.

Field, T., 2010. Touch for socioemotional and physical well-being: a review. Dev. Rev. 30, 367-383.

\footnotetext{
${ }^{1}$ References marked with an asterisk indicate studies included in the metaanalysis.
}

Fleming, A.S., Corter, C., Stallings, J., Steiner, M., 2002. Testosterone and prolactin are associated with emotional responses to infant cries in new fathers. Horm. Behav. 42 (4), 399-413.

Gazzola, V., Spezio, M.L., Etzel, J.A., Castelli, F., Adolphs, R., Keysers, C., 2012. Primary somatosensory cortex discriminates affective significance in social touch. Proc. Natl. Acad. Sci. U. S. A. 109 (25), E1657-66.

Georgiadis, J.R., Farrell, M.J., Boessen, R., Denton, D.A., Gavrilescu, M., Kortekaas, R., et al., 2010. Dynamic subcortical blood flow during male sexual activity with ecological validity: a perfusion fMRI study. Neuroimage 50 (1), 208-216.

Georgiadis, J.R., Holstege, G., 2005. Human brain activation during sexual stimulation of the penis. J. Comp. Neurol. 493 (1), 33-38.

Gray, P.B., Kahlenberg, S.M., Barrett, E.S., Lipson, S.F., Ellison, P.T., 2002. Marriage and fatherhood are associated with lower testosterone in males. Evol. Hum. Behav. 23 (3), 193-201. https://doi.org/10.1016/S1090-5138(01)00101-5.

Grebe, N.M., Sarafin, R.E., Strenth, C.R., Zilioli, S., 2019. Pair-bonding, fatherhood, and the role of testosterone: a meta-analytic review. Neurosci. Biobehav. Rev. 98, 221-233. https://doi.org/10.1016/j.neubiorev.2019.01.010.

Hall, J.A., 1996. Touch, status, and gender at professional meetings. J. Nonverbal Behav. 20 (1), 23-44. https://doi.org/10.1007/BF02248713.

Hall, J.A., Coats, E.J., LeBeau, L.S., 2005. Nonverbal behavior and the vertical dimension of social relations: a meta-analysis. Psychol. Bull. 131 (6), 898.

Henley, N.M., 1973. The politics of touch. In: Brown, P. (Ed.), Radical Psychology. Tavistock, London, pp. 420-433.

Hertenstein, M.J., Campos, J.J., 2001. Emotion regulation via maternal touch. Infancy 2 (4), 549-566. https://doi.org/10.1207/S15327078IN0204_09.

Hertenstein, M.J., Keltner, D., 2011. Gender and the communication of emotion via touch. Sex Roles 64 (1-2), 70-80.

Hertenstein, M.J., Verkamp, J.M., Kerestes, A.M., Holmes, R.M., 2006. The communicative functions of touch in humans, nonhuman primates, and rats: a review and synthesis of the empirical research. Genet. Soc. Gen. Psychol. Monogr. 132 (1), 5-94.

*Hielscher, E., Mahar, D., 2016. An exploration of the interaction between touch avoidance and the pleasant touch (C-Tactile afferent) system. Perception 46 (1), 18-30. https://doi.org/10.1177/0301006616661938.

Higgins, J.P.T., Green, S., 2011. Cochrane Handbook for Systematic Reviews of Interventions, Version 5.1.0. Retrieved from www.cochranehandbook.org.

Iggo, A., 1960. Cutaneous mechanoreceptors with afferent C fibres. J. Physiol. 152 (2), 337-353.

Jean, A.D., Stack, D.M., Fogel, A., 2009. A longitudinal investigation of maternal touching across the first 6 months of life: age and context effects. Infant Behav. Dev. 32 (3), 344-349. https://doi.org/10.1016/j.infbeh.2009.04.005.

Jönsson, E.H., Backlund Wasling, H., Wagnbeck, V., Dimitriadis, M., Georgiadis, J.R., Olausson, H., Croy, I., 2015. Unmyelinated tactile cutaneous nerves signal erotic sensations. J. Sex. Med. 12 (6), 1338-1345. https://doi.org/10.1111/jsm.12905.

Jönsson, E.H., Bendas, J., Weidner, K., Wessberg, J., Olausson, H., Backlund Wasling, H., Croy, I., 2017. The relation between human hair follicle density and touch perception. Sci. Rep. 7, 2499. https://doi.org/10.1038/s41598-017-02308-9.

Kandel, E.R., Schwartz, J.H., Jessell, T.M., 2013. New York. Principles of Neural Science, fifth ed. McGraw Hill Professional.

*Kass-Iliyya, L., Leung, M., Marshall, A., Trotter, P., Kobylecki, C., Walker, S., Gosal, D., Jeziorska, M., Malik, R.A., McGlone, F., Silverdale, M.A., 2016. The perception of affective touch in Parkinson's disease and its relation to small fibre neuropathy. Eur. J. Neurosci. 45 (2), 232-237. https://doi.org/10.1111/ejn.13481.

Krahé, C., von Mohr, M., Gentsch, A., Guy, L., Vari, C., Nolte, T., Fotopoulou, A., 2018. Sensitivity to CT-optimal, affective touch depends on adult attachment style. Sci. Rep. 8, 14544. https://doi.org/10.1038/s41598-018-32865-6.

Lee, J.W., Guerrero, L.G., 2001. Types of touch in cross-sex relationships between coworkers: perceptions of relational and emotional messages, inappropriateness, and sexual harassment. J. Appl. Commun. Res. 29, 197-220.

Liljencrantz, J., Olausson, H., 2014. Tactile C fibers and their contributions to pleasant sensations and to tactile allodynia. Front. Behav. Neurosci. 8, 37. https://doi.org/10. 3389/fnbeh.2014.00037.

Liu, Q., Vrontou, S., Rice, F.L., Zylka, M.J., Dong, X., Anderson, D.J., 2007. Molecular genetic visualization of a rare subset of unmyelinated sensory neurons that may detect gentle touch. Nat. Neurosci. 10 (8), 946.

*Löken, L.S., Evert, M., Wessberg, J., 2011. Pleasantness of touch in human glabrous and hairy skin: order effects on affective ratings. Brain Res. 1417, 9-15. https://doi.org/ 10.1016/j.brainres.2011.08.011.

Löken, L.S., Wessberg, J., Morrison, I., McGlone, F., Olausson, H., 2009. Coding of pleasant touch by unmyelinated afferents in humans. Nat. Neurosci. 12 (5), 547-548. https://doi.org/10.1038/nn.2312.

*Macefield, V.G., Norcliffe-Kaufmann, L., Löken, L., Axelrod, F.B., Kaufmann, H., 2014. Disturbances in affective touch in hereditary sensory and autonomic neuropathy type III. Int. J. Psychophysiol. 93 (1), 56-61. https://doi.org/10.1016/j.ijpsycho.2014.04. 002.

Maitre, N.L., Key, A.P., Chorna, O.D., Slaughter, J.C., Matusz, P.J., Wallace, M.T., Murray, M.M., 2017. The dual nature of early-life experience on somatosensory processing in the human infant brain. Curr. Biol. 27 (7), 1048-1054. https://doi.org/10.1016/j. cub.2017.02.036.

Major, B., 1981. Gender patterns in touching behavior. In: Mayo, C., Henley, N.M. (Eds.), Gender and Nonverbal Behavior. Springer Series in Social Psychology. Springer, New York. https://doi.org/10.1007/978-1-4612-5953-4_2.

Marx, V., Nagy, E., 2017. Fetal behavioral responses to the touch of the mother's abdomen: a Frame-by-frame analysis. Infant Behav. Dev. 47, 83-91.

Mazur, A., Booth, A., 1998. Testosterone and dominance in men. Behav. Brain Sci. 21, 353-397.

Meh, D., Denišlič, M., 1994. Quantitative assessment of thermal and pain sensitivity. J. 
Neurol. Sci. 127 (2), 164-169. https://doi.org/10.1016/0022-510X(94)90069-8.

Moher, D., Liberati, A., Tetzlaff, J., Altman, D.G., 2010. Preferred reporting items for systematic reviews and meta-analyses: the PRISMA statement. Int. J. Surg. 8 (5), 336-341. https://doi.org/10.1016/j.ijsu.2010.02.007.

Nelson, C.A., Fox, N.A., Zeanah, C.H., 2014. Romania's Abandoned Children. Deprivation, Brain Development, and the Struggle for Recovery. Harvard University Press, Cambridge.

Olausson, H., Wessberg, J., Morrison, I., McGlone, F., Vallbo, A., 2010. The neurophysiology of unmyelinated tactile afferents. Neurosci. Biobehav. Rev. 34, 185-191. https://doi.org/10.1016/j.neubiorev.2008.09.011.

Perini, T., Ditzen, B., Fischbacher, S., Ehlert, U., 2012. Testosterone and relationship quality across the transition to fatherhood. Biol. Psychol. 90 (3), 186-191.

*Sailer, U., Triscoli, C., Haggblad, G., Hamilton, P., Olausson, H., Croy, I., 2016. Temporal dynamics of brain activation during $40 \mathrm{~min}$ of pleasant touch. NeuroImage 139, 360-367. https://doi.org/10.1016/j.neuroimage.2016.06.031.

Scheele, D, Kendrick, K.M., Khouri, C., Kretzer, E, Schläpfer, T.E., Stoffel-Wagner, B., Güntürkün, O., Maier, W., Hurlemann, R., 2014. An oxytocin-induced facilitation of neural and emotional responses to social touch correlates inversely with autism traits. Neuropsychopharmacology 39, 2078-2085.

Sehlstedt, I., Ignell, H., Backlund Wasling, H., Ackerley, R., Olausson, H., Croy, I., 2016. Gentle touch perception across the lifespan. Psychol. Aging 31 (2), 176-184. https:// doi.org/10.1037/pag0000074.

Sharp, H., Pickles, A., Meaney, M., Marshall, K., Tibu, F., Hill, J., 2012. Frequency of infant stroking reported by mothers moderates the effect of prenatal depression on infant behavioural and physiological outcomes. PLoS One 7 (10), e45446. https:// doi.org/10.1371/journal.pone.0045446.

Song, F., Hooper, L., Loke, Y., 2013. Publication bias: what is it? How do we measure it? How do we avoid it? Open Access J. Clin. Trials 5 (1), 51-81. https://doi.org/10. 2147/OAJCT.S34419.

Stack, D.M., LePage, D.E., Hains, S., Muir, D.W., 1996. Qualitatitive changes in maternal touch as a function of instructional condition during face-to-face social interactions. Infant Behav. Dev. 19, 761.

Stack, D.M., Muir, D.W., 1992. Adult tactile stimulation during face-to-face interactions modulates five-month-olds' affect and attention. Child Dev. 63 (6), 1509-1525.

Stier, D.S., Hall, J.A., 1984. Gender differences in touch: an empirical and theoretical review. J. Pers. Soc. Psychol. 47 (2), 440-459. https://doi.org/10.1037/0022-3514. 47.2.440.

Suvilehto, J.T., Glerean, E., Dunbar, R.I.M., Hari, R., Nummenmaa, L., 2015. Topography of social touching depends on emotional bonds between humans. Proc. Natl. Acad. Sci. U. S. A. 112 (45), 13811-13816. https://doi.org/10.1073/pnas.1519231112.

Suvilehto, J.T., Nummenmaa, L., Harada, T., Dunbar, R., Hari, R., Turner, R., et al., 2019. Cross-cultural similarity in relationship-specific social touching. Proc. Biol. Sci. 286 (1901), 20190467. https://doi.org/10.1098/rspb.2019.0467.

Takeuchi, M.S., Miyaoka, H., Tomoda, A., Suzuki, M., Liu, Q., Kitamura, T., 2010. The effect of interpersonal touch during childhood on adult attachment and depression: a neglected area of family and developmental psychology? J. Child Fam. Stud. 19 (1), 109-117.

Triscoli, C., Ackerley, R., Sailer, U., 2014. Touch satiety: differential effects of stroking velocity on liking and wanting touch over repetitions. PLoS One 9 (11), e113425. https://doi.org/10.1371/journal.pone.0113425.

*Triscoli, C., Olausson, H., Sailer, U., Ignell, H., Croy, I., 2013. CT-optimized skin stroking delivered by hand or robot is comparable. Front. Behav. Neurosci. 7 (208). https:// doi.org/10.3389/fnbeh.2013.00208.

Trumble, B.C., Smith, E.A., O'Connor, K.A., Kaplan, H.S., Gurven, M.D., 2014. Successful hunting increases testosterone and cortisol in a subsistence population. Proc. R. Soc. B: Biol. Sci. 281 (1776). https://doi.org/10.1098/rspb.2013.2876.

Vallbo, A., Loken, L., Wessberg, J., 2016. Sensual touch: a slow touch system revealed with microneurography. In: Olausson, H., Wessberg, J., Morrison, I., McGlone, F. (Eds.), Affective Touch and the Neurophysiology of CT Afferents. Springer, New York, pp. 1-30. https://doi.org/10.1007/978-1-4939-6418-5_1.

Vallbo, A.B., Olausson, H., Wessberg, J., 1999. Unmyelinated afferents constitute a second system coding tactile stimulus of the human hairy skin. J. Neurophysiol. 81 (6), 2753-2763. https://doi.org/10.1152/jn.1999.81.6.2753.

van Anders, S.M., Tolman, R.M., Volling, B.L., 2012. Baby cries and nurturance affect testosterone in men. Horm. Behav. 61 (1), 31-36. https://doi.org/10.1016/j.yhbeh. 2011.09.012.

Walker, S.C., McGlone, F.P., 2013. The social brain: neurobiological basis of affiliative behaviours and psychological well-being. Neuropeptides 47 (6), 379-393.

Walker, S.C., Trotter, P.D., Swaney, W.T., Marshall, A., Mcglone, F.P., 2017. C-tactile afferents: Cutaneous mediators of oxytocin release during affiliative tactile interactions? Neuropeptides 64, 27-38.

Webb, A., Peck, J., 2015. Individual differences in interpersonal touch: on the development, validation, and use of the "comfort with interpersonal touch" (CIT) scale. J. Consum. Psychol. 25 (1), 60-77.

Weisman, O., Zagoory-Sharon, O., Feldman, R., 2014. Oxytocin administration, salivary testosterone, and father-infant social behavior. Prog. Neuropsychopharmacol. Biol. Psychiatry 49, 47-52. https://doi.org/10.1016/j.pnpbp.2013.11.006.

Weiss, S.J., Wilson, P., Hertenstein, M.J., Campos, R., 2000. The tactile context of a mother's caregiving: implications for attachment of low birth weight infants. Infant Behav. Dev. 23 (1), 91-111. https://doi.org/10.1016/S0163-6383(00)00030-8.

Wells, G.A., Shea, B., O'Connell, D., Peterson, J., Welch, V., Losos, M., Tugwell, P., 2011 The Newcastle-Ottawa Scale (NOS) for assessing the quality of nonrandomised studies in meta- analyses. J. Mark. Manage. 27, 808-833. https://doi.org/10.1080/ 0267257X.2010.500136.

Wessberg, J., Olausson, H., Fernström, K.W., Vallbo, A.B., 2003. Receptive field properties of unmyelinated tactile afferents in the human skin. J. Neurophysiol. 89 (3), 1567-1575.

Worthman, C.M., Konner, M.J., 1987. Testosterone levels change with subsistence hunting effort in Kung San Men. Psychoneuroendocrinology 12 (6), 449-458. 